\title{
URBANIZACIÓN DE LA SOCIEDAD AGRARIA VASCA: EL CASERÍO DEL PERIURBANO DE SAN SEBASTIÁN*
}

\author{
Juan Cruz Alberdi Collantes \\ Departamento de Geografía, Universidad del Pais Vasco, Facultad de Filología, \\ Geografía e Historia, Francisco Tomás y Valiente s/n, Apartado 2111 \\ 01006 VITORIA-GASTEIZ. Correo electrónico: fgpalco@vc.ehu.es
}

\begin{abstract}
Resumen: Centrándonos en algunos atributos que han caracterizado a la sociedad rural vasca, profundizamos en los cambios que observamos en los últimos años y en las implicaciones espaciales que éstos están originando. Concretamente, centramos nuestra atención en la institución del mayorazgo, organizadora del primer ámbito social del individuo rural, la casa. Observamos que esta institución va perdiendo su razón de ser y deja de funcionar, dividiéndose los bienes inmuebles del caserio entre todos los hermanos y dificultando la consecución de explotaciones agrarias "suficientes". La aldea, segundo ámbito comunitario, también se ve sustituida, dejando paso a las relaciones familiares. En definitiva, observamos cómo el medio social que rodea al caserío comienza a regirse por atributos urbanos.
\end{abstract}

Palabras clave: Caserio, San Sebastián, Paîs Vasco, agricultura, población agrícola, sociedad rural.

\begin{abstract}
In this paper we investigate the last changes in and the space implications that they are challenging, taking to account the analysis of some elements of the rural basque society. So, we direct our investigation to the study of the distribution of the family heritage (mayorazgo), because the basque rural society is organised around it. In that moment, the mayorazgo institution is leaving his function and the family heritage is splitting among the brothers. As consequence, the farm production is left because the new farms don't have enough flour. The village, the second social space after the family house, is leaving change by the family relations. So, the rural basque society, in that moment, is directed by the urban society near it.
\end{abstract}

Key words: Farm population, San Sebastian, Basque country, agriculture, rural society.

\footnotetext{
* Recibido: 8-3-2001. Aceptado: 9-7-2001
} 
El sistema agrario que caracteriza al caserío vasco aparentemente se mantiene en sus fundamentos básicos en el último cuarto de siglo. Los primeros datos del censo agrario de 1999 no muestran alteraciones significativas y usos, explotaciones y actividades, en términos generales, conservan su anterior presencia.

Observamos que, a pesar de ello, ya esta iniciado un proceso que lleva a la consecución de un nuevo escenario en el medio rural vasco-atlántico, un espacio sin agricultores. Cambia el sistema productivo, la dinámica poblacional, los usos del suelo y también el espacio social que rodea al caserío.

En este artículo profundizamos en la influencia que la proximidad urbana y la reestructuración agrícola están teniendo en el espacio social del caserío del periurbano de San Sebastián, incidencia que, presumiblemente, va a tener unas profundas repercusiones espaciales. Recurrimos para ello al estudio de los cambios acaecidos en dos ámbitos sociales distintos como son la casa y la aldea, analizando las alteraciones observadas en algunas de las instituciones que surguen en torno a éstos, como es el mayorazgo o el "auzolan" o trabajo comunitario.

La comarca de San Sebastián, a pesar de ser claramente urbana, presenta una explotación agraria con una orientación, usos y evolución similar a la del caserío

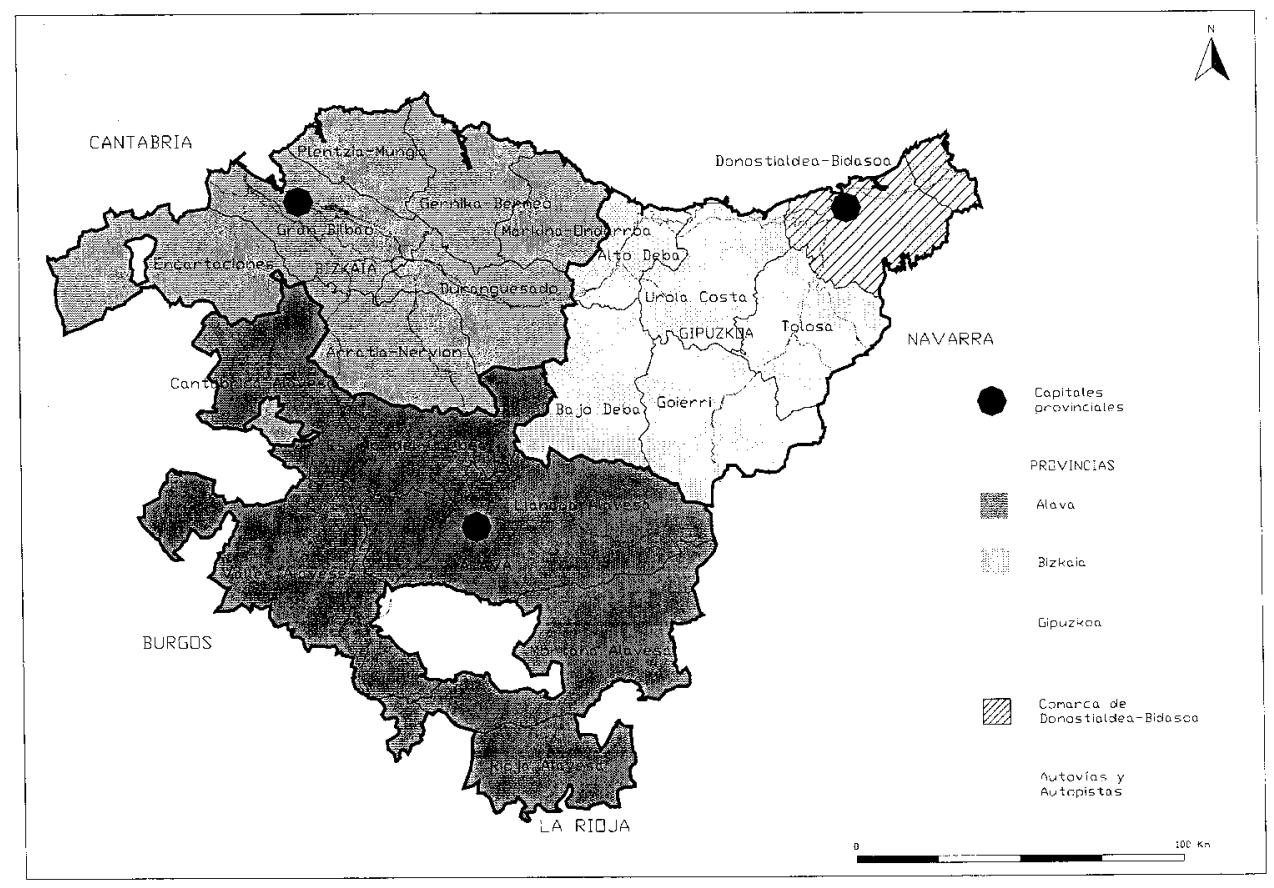

Figura 1. Localización de la comarca de Donostaldea-Bidasoa 
medio de Gipuzkoa y de Bizkaia. En términos generales, podemos considerar al caserío de estas provincias como una tipología de explotación agraria propia de espacios periurbanos. (Figura 1. Donostialdea-Bidasoa en la Comunidad Autónoma Vasca).

\section{La ciudad en la estructura social del medio rural}

La influencia de la ciudad en el medio rural que la circunda alcanza también al espacio habitual de las sociedades rurales más alejadas, transformándolo y, en gran medida, urbanizándolo.

Redfield (1947) define un tipo ideal de sociedad rural, como polo opuesto a la urbana. Se caracteriza por una colectividad pequeña, aislada y homogénea, con un fuerte sentido solidario de grupo. El comportamiento es tradicional, espontáneo, crítico y personal; no hay legislación o hábito de experiencia y reflexión con fines intelectuales. El parentesco, sus relaciones e instituciones son categorías, y el grupo familiar es la unidad de acción (Cit. González Encinar, 1984: 117).

Aunque no hay ningún grupo que se corresponda exactamente con una estructura como la señalada, son las colectividades agrarias, definidas como aquellas en las que la producción agropecuaria constituye el marco de la organización social y económica, fundamentadas en su autosuficiencia, las que mejor determinan el tipo ideal señalado.

Esta comunidad autárquica, en la medida en que entra en una economía de mercado y en un modelo industrial, tiene dificultades para reproducir algunas de sus unidades básicas y entra en crisis. La quiebra originada es generalizada y modelos y valores urbanos comienzan a imponerse sobre aquellos que definían a estos grupos.

Siguiendo las afirmaciones de Firey, Loonis y Begle (1957), la fusión del campo y de la ciudad provoca toda una serie de consecuencias, al menos en tres aspectos diferentes (Cit. González Encinar, 1984: 114).

- Las familias agrícolas son menos rurales por la proximidad de la ciudad y por el contacto cotidiano con personas de cultura urbana, que crean nuevos asentamientos en vecindad con los rurales.

- La reordenación del modelo de asentamiento rural provoca cambios en la interacción social-rural. Se ha acabado con el aislamiento que caracterizó la vida rural y se ha roto el agrupamiento estable y local que ha sido el fundamento de la vida rural. 
- Estas alteraciones son reflejo de un cambio de cultura. Pero mientras que la comunicación es siempre un proceso en dos direcciones, la difusión del nuevo modelo cultural lo es en una única dirección. Con las debidas salvedades, un principio general parece válido: las áreas rurales, en proporción directa a su proximidad a centros urbanos, están siendo culturalmente urbanizadas.

Parece evidente que el medio y la cultura urbana influyen de manera decisiva en el espacio rural y en la población que trabaja en la agricultura. Uno de los aspectos que más trascendencia tiene es la llegada de población exterior al medio rural ${ }^{1}$. Este fenómeno no es exclusivo de zonas rurales próximas a la ciudad y muchas zonas alejadas alojan ahora nuevos habitantes ${ }^{2}$.

Las motivaciones que llevan a tomar la decisión de ir a vivir al espacio rural son varias. Atendiendo a las que recoge Kayser, cabe señalar razones de prestigio, de revalorización ideológica de la vida en el campo, calidad del hábitat y, especialmente, búsqueda de un mayor nivel de vida (1990).

Los espacios rurales son ahora requeridos como residencia y gran parte de los habitantes urbanos sueñan con una casa en el campo. Sin embargo, este fenómeno nada tiene que ver con una vuelta a la función que principalmente se ha desarrollado en él, la agricultura. En el Departamento de Lot (Francia) no alcanza al 4\% el porcentaje de nuevos residentes que comienza a trabajar en esta actividad (Kayser, 1990).

La llegada de nuevos habitantes afecta a la organización de la sociedad rural. Surgen nuevos intereses y actividades económicas y, en general, se rompe con la estructura tradicional. Los jóvenes rurales siguen experimentando diferencias en cuanto a oportunidades laborales, educativas, culturales y de ocio y continúan alimentando la corriente del éxodo rural. Entre los inmigrantes domina la población retirada, que busca una mayor calidad de vida en este medio. Como resultado se acentúa aún más la desagrarización de estos espacios.

Sin embargo, la razón más señalada a la hora de justificar la quiebra de la colectividad rural está relacionada con los cambios socioeconómicos que se han ido gestando a partir de los mecanismos de integración del ámbito agrario en una economía de mercado desde principios del siglo XX.

Especial relevancia tienen las alteraciones acaecidas en la última mitad del siglo XX. Comas d'Argemir y Contreras resaltan este aspecto, observando en los estudios realizados en la década de los años sesenta-setenta una sociedad rural relativamente cerrada, fundamentada en su autosuficiencia. La ruptura social se produce cuando comienza a materializarse una apertura al mundo exterior (1996).

Es posible que la incidencia de los modos de vida urbanos fuera anterior a la etapa de desarrollismo vivida a partir de la década de los años sesenta ${ }^{3}$, pero es en este 
momento cuando se comienza a materializar un giro que está siendo trascendental en el cambio social que se está produciendo y que está provocando que elementos tradicionales de la comunidad rural estén desapareciendo.

Una vez más, las transformaciones acaecidas como consecuencia de la progresiva adecuación de las actividades agrarias a las reglas de la economía de mercado tienen su reflejo en aspectos característicos del mundo rural. Como señala Sancho, "los recientes procesos de mundialización del mercado, incluido el agrario, la extensión de las comunicaciones y las pautas alimentarias han dado lugar a nuevos procesos sincréticos entre los elementos de aculturación urbana y las tradiciones agrarias y campesinas que diluyen los límites de lo rural tradicional" (1997).

Si durante mucho tiempo la identidad rural ha estado unida a lo agrario y campesino, actualmente esta relación está cada vez más cuestionada. El agricultor ya no es mayoritario en su medio y el orden social centrado en torno a esta actividad cada vez tiene menos peso. La tierra, componente necesario para la supervivencia de la familia, pierde importancia como elemento de diferenciación social y de prestigio y con la apertura al exterior del ámbito rural se evidencia todo lo que tiene la ciudad y todo de lo que carece el campo.

Con la pérdida de homogeneidad y aislamiento del grupo rural, las particularidades sociales también se reducen. Se tiende a señalar que apenas hay diferencias entre el mundo rural y el urbano, ni económicas, ni culturales, ni sociales ${ }^{4}$. El medio rural adquiere nuevas funciones que, atendiendo a las aportaciones de Camarero (1997), se podrían sintetizar en la sustitución de la calidad agrológica del espacio, en cuanto factor de progreso, por la calidad ambiental, fuente hipotética pero aún así generadora de desarrollo. Como señala el mismo autor, "Nos movemos pero la geografía del territorio ya no cambia. Los lugares son los mismos aunque cambiamos de lugar..

El ámbito rural vasco participa de esta tendencia general. La ciudad tiene cada vez mayor presencia en todo el espacio rural. El fenómeno y las fechas concuerdan con las observadas en España y la intensidad, si cabe, es aún mayor. En este sentido, Arpal ya señalaba que “Vizcaya y Guipúzcoa aparecen (dentro de los límites provinciales) como provincias en las que lo rural ha sufrido a lo largo del presente siglo un claro proceso de reducción, aunque se presente algún titubeo en el decenio identificable con la guerra civil y el comienzo de la postguerra. Han sido, sobre todo, las magnitudes alcanzadas por esta transformación en el decenio 1960-70 las que han llevado a clasificar al campo guipuzcoano y vizcaíno como un área de actividad residual, marginal o de puro interés histórico-etnográfico» (1979: 91).

El espacio social del ámbito rural se encontraba ordenado preferentemente en torno al solar o caseríos. Del equilibrio que se creaba hoy en día apenas nos quedan escasos ejemplos. La familia troncal, modalidad que englobaba en la misma unidad hasta tres generaciones distintas, ha ido progresivamente desapareciendo a partir del 
momento en que sus miembros acudían a trabajar a ese mundo urbano. A medida que el caserío pierde su función productiva el mayorazgo, institución que cumple la función de mantener en su integridad los bienes inmuebles de la casa, es fuertemente cuestionado. Todos los miembros de la familia quieren heredar por igual y recibir su dote principalmente en forma de vivienda o de tierras. Ello lleva irremediablemente a la división del dominio familiar en unidades más pequeñas en las que el desarrollo de las funciones agrarias pierden importancia frente a las residenciales.

Incluso la aldea, ámbito social inmediato, pierde su anterior papel con la generalización de la movilidad de la población y la pérdida de homogeneidad en las funciones de sus habitantes ${ }^{6}$. Con ello, las relaciones de vecindad, necesarias en el funcionamiento de una sociedad agrícola y que adquieren carácter de obligatoriedad para el medio rural e incluso para toda la sociedad vasca pierden ahora su razón de ser. A medida que estas formas de organización dejan de servir a sus propósitos originales, inician un proceso que lleva a su desaparición.

Es de esperar que un modelo de organización colectivo, fundamentado en la propiedad de la tierra y en la explotación de sus posibilidades agroganaderas, una vez que altere su cometido pierda su razón de ser y los cambios en su estructura se sucedan por sí mismos. Inmerso en este proceso encontramos al caserío del País Vasco y del periurbano de San Sebastián, con una estructura de organización familiar, el mayorazgo, y con un modelo de relación vecinal, el trabajo de la comunidad o aauzolan", en fase de mutación.

\section{El mayorazgo: quiebra social e implicaciones territoriales}

El mayorazgo parte de una costumbre afianzada en el caserío vasco destinada finalmente a evitar la división de la explotación y la excesiva fragmentación de la tierra. Para ello, se designaba a uno de los hijos como único heredero, al que le correspondía continuar al frente de la casa.

Es, ante todo, un modelo de organización familiar. En la misma unidad convivian normalmente tres generaciones distintas, la pareja mayor, la joven y los hijos de estos. Junto a ellos habitualmente vivían hermanos y hermanas de distintas generaciones e incluso criados o sirvientas que no eran familiares. La base económica que sustentaba el caserío estaba fundamentada en un modelo agrícola o ganadero autosuficiente. Los bienes eran muebles e inmuebles y entre estos últimos, principalmente la tierra y la casa familiar, que había que procurar mantener en su integridad en cuanto que eran elementos fundamentales para sostener ese modelo de vida. Para que el sistema fuera viable, los bienes inmuebles se cedían en su totalidad a un hijo o hija, e incluso algunos de los muebles, especialmente los relacionados con los inmuebles? 
El mantenimiento de la casa y de la tierra en manos de una única persona no estaba establecido exclusivamente por la realidad económica. Este sistema tenía también una clara implicación social. La pertenencia a la casa o al solar era condición fundamental para formar parte en las mismas condiciones de la comunidad que imperaba en ese momento.

El sistema socio-económico desarrollado en el caserío vasco no es sino un reflejo de la estructura de los estamentos superiores de la sociedad, extendida ahora a otros estamentos sociales ${ }^{8}$. En nuestro caso, además, al tener el padre la potestad de elegir al que iba a ser el heredero, su autoridad va a ser fundamental para asegurar el mantenimiento y la continuidad del sistema?

El modelo organizativo, sin embargo, comienza a alterarse progresivamente desde mediados del siglo XIX. En primer lugar cambian algunos valores sociales, principalmente a partir de la difusión de las ideas del liberalismo: "comienza a desarrollarse la familia nuclear; la propiedad privada frente a la comunal, los derechos individuales de la persona por encima de los colectivos, la pérdida de importancia del apellido y de la pertenencia a la casa familiar ..." (Urrutikoetxea, 1992: 464).

La ruptura definitiva se produce cuando la agricultura, fundamento económico de la comunidad tradicional, empieza a cambiar y a perder trascendencia. Esta variación viene preferentemente de la mano de la industrialización. "La propia institucionalización del tenente-propietario se convierte en un freno a la rentabilidad, dada la exigüidad de las parcelas. Todos los estudiosos de la "crisis del caserío" o los investigadores del "caserío rentable" apuntan la importancia de una ampliación del tamaño de las explotaciones para hacer frente a las exigencias modernas de la producción agraria" (Arpal, 1979: 102).

Las nuevas actividades económicas demandan mano de obra y la propia renovación biológica del caserío, que antes ni se planteaba al convivir multitud de miembros familiares en la misma unidad, comienza a quedar en entredicho. La falta de mujeres se hace cada vez más evidente e influye de manera decisiva en su desarrollo como unidad agraria. El tener descendencia directa es condición necesaria para que se dinamice el caserío como explotación y vivienda y aquel que no la posee inicia una fase de retroceso ${ }^{10}$.

Por tanto, con la extensión de la sociedad urbano-industrial, el caserío pierde su coherencia y sistema de reproducción anterior, el mercado acaba con el autoabastecimiento, las migraciones liquidan un elemento fundamental como es su reproducción demográfica e incluso la tecnología pone en entredicho su capacidad como explotación agraria.

Sin embargo, estos procesos no son siempre ni tan generalizados ni tan inmediatos. Desde la óptica del geógrafo, tienen especial relevancia los cambios espaciales 
que este fenómeno origina. A pesar de la crisis de la figura del mayorazgo, el agricultor no es partidario de dividir los bienes inmuebles, especialmente la tierra, necesaria para mantener una estructura productiva mínima. Fruto de ello, el caserío ha llegado hasta la década de los noventa básicamente intacto, al menos en cuanto a base territorial se refiere. La explotación media que se refleja en los registros de explotaciones presenta en esta comarca una superficie agraria utilizable similar a la que ya otros investigadores, en otros momentos, habían apuntado ${ }^{11}$.

Sin embargo, esta estructura empieza a mostrar indicios de cambio a partir de la década de los ochenta y será en los inicios de la primera del 2000 cuando comiencen a materializarse. En este momento se está consumando el cambio generacional en la jefatura de la explotación y, en algunos casos, también en la titularidad. Se comienza a configurar la estrategia que va a definir la distribución de los bienes entre unos familiares plenamente integrados y partícipes de una sociedad urbana.

Arrieta (1998), desde una óptica antropológica, describe cómo se van desarrollando estas reparticiones, centrando sus investigaciones en un municipio del periurbano de San Sebastián, Oiartzun. A partir del análisis de varios ejemplos, llega a la conclusión de que la situación más extendida es aquella en la que los hijos e hijas, residan o no en el caserío, reciben o recibirán una parte compensatoria similar, preferentemente en bienes inmuebles. A su vez, observa cómo la partición genera la vuelta de alguno de los hijos que habitaba en el medio urbano al campo, bien a través de la construcción de una nueva vivienda o bien dividiendo la residencia familiar.

Este proceso nos sitúa ante una nueva concepción de la sociedad rural y del espacio productivo, que retoma plenamente valores propios de la cultura urbana. Para comprenderlo tenemos que tener en cuenta, al menos, estos elementos:

- En ninguno de los ejemplos hay hijos que vivan exclusivamente o preferentemente de la agricultura. En Oiartzun, las explotaciones agroganaderas de dedicación exclusiva, al frente de las cuales está una persona joven, son una excepción. Es una población empleada en el exterior y como se recoge, preferentemente vive en el exterior.

- Los padres no imponen su autoridad a la hora de repartir la herencia y cuando lo quieren hacer, son los hijos los que toman la decisión de dividir el dominio de manera igualitaria. Aunque siempre hay excepciones, predomina la consideración igualitaria de todos los miembros de la familia, vivan o no, colaboren o no, en la explotación.

- La legislación que ha.estado en vigor hasta el año 1999 en el territorio histórico guipuzcoano en cuanto a las herencias de las explotaciones agrarias se regulaba a partir del Código Civil Español, según el cual, a la muerte de la persona titu- 
lar al menos la tercera parte de la propiedad, o su equivalente en dinero, debía ser repartido a partes iguales entre todos los hijos e hijas. Esto permitía a aquel vástago disconforme recurrir la decisión ante los tribunales. Ante esto, la opción que le quedaba al elegido era la de vender parte de los bienes, con la consiguiente fragmentación del dominio, o pagar en metálico la parte correspondiente al resto de herederos, lo cual le obliga a pedir créditos y a endeudarse. Es normal que los hermanos traten de buscar una salida lo más consensuada posible.

De confirmarse esta orientación como generalizada, la superficie que el caserío tiene en propiedad se vería aún más reducida. La parcelación tiene un tope legal, la unidad mínima de cultivo, que en el territorio guipuzcoano es de una hectárea ${ }^{12}$. El resultado generaría la consecución de unas explotaciones agroganaderas aún más limitadas en cuanto a base territorial de lo que son actualmente, reduciendo también las posibilidades de desarrollo de esta actividad.

La proximidad a la ciudad contribuye a que la subdivisión se materialice. El valor de terrenos y vivienda se ha disparado, escapando de toda lógica productiva. La compensación monetaria cada vez es más dificultosa y los beneficiarios prefieren recibir su herencia en bienes inmuebles. A ello contribuye la revalorización social de la vivienda rural y de la vida en el campo. Muchos de los herederos quieren volver nuevamente a residir en el medio rural, preferentemente en una morada individual. Al poseer parcelas en propiedad tratan de construir en ellas o, en otros casos, dada la demanda existente, procurarán venderlas con licencia de edificación. Para esta población, la capacidad agrológica del suelo apenas tiene significado y lo que le da el valor real a la hacienda son sus posibilidades residenciales. Por ello, la base territorial del caserío se divide rápidamente pues ningún beneficiario busca una compensación monetaria $a^{13}$.

La normativa municipal, en este caso de Oiartzun, facilita, en cierta medida, este proceso en cuanto que permite construir una segunda residencia a aquellos caseríos que posean en propiedad más de $4 \mathrm{Ha}$, tengan o no dedicación agrícola, además de dar opción a subdividir la vivienda familiar.

Hasta ahora nos hemos fundamentado en apreciaciones recogidas a partir de una serie de ejemplos de una investigación reciente. Nosotros no hemos profundizado en el trabajo de campo realizado en la decisión que cada caserío tomaba en relación al reparto de los bienes inmuebles ${ }^{14}$ pero sí hemos realizado toda una serie de consultas sobre distintos aspectos de la explotación, entre otros, sobre la composición de la población que vivía en el caserío y sobre la ayuda familiar que recibían, que nos hace suponer una serie de situaciones que merecen una reflexión y que nos ayudan a medir la posible extensión de este fenómeno.

Tomando como referencia el municipio de Usurbil procedemos a entrevistar a la totalidad de los caseríos de esta localidad (143 entrevistas). Para ello contamos con 
la colaboración de distintas personas ligadas al medio rural del municipio, lo que nos permite mantener una conversación extendida sobre multitud de aspecto de cada explotación. Optamos por una entrevista abierta, sin un guión establecido y que nunca es configurada en la propia vivienda. A pesar de la escasa defición de algunos temas sí nos permite estructurar el funcionamiento, la evolución y perspectivas de cada explotación.

Partimos del supuesto de que la edad de 30 años puede ser adecuada como punto de inflexión entre una persona que se va a quedar a residir en el caserío y aquélla que comienza a hacer vida independiente fuera de él. Si una vez superada esa edad continuaba residiendo en la vivienda familiar suponíamos que también lo haría en el futuro ${ }^{15}$, si tenía opción a ello.

En muchos ejemplos nos topábamos con que, además de los padres, residian tíos solteros en el caserío. Desconocemos la parte de la heredad que correspondía a cada uno. En este caso, consideramos que los mayores de 50 años, de ser así, cederían a los sobrinos, si los tenían, la parte que les correspondía, si no inmediatamente, sí en el futuro, con lo que la explotación se mantendría íntegra.

Por tanto, en Usurbil, a través de 131 muestras, contamos con información de la estructura familiar que habita en su caserío e, incluso, con apuntes relativos a la población que, no residiendo en él, acude a ayudar en los trabajos de la explotación. En esta muestra se intuyen realidades distintas:

- La situación más repetida es aquella en la que más de un hijo mayor de 30 años reside todavía en el caserío, junto a sus padres, los abuelos e incluso algún tío, todos ellos jubilados o en situación próxima a la jubilación. En algunos casos, además, también habitan con ellos hermanos menores de 30 años (40 caseríos).

- Otra grupo importante es aquél en el que se evidencia que es un único descendiente, mayor de 30 años, el que se queda con los padres o tíos mayores de 50 años. Éste, a su vez, puede estar casado y tener familia. Con un solo hijo tenemos 30 casos y otros tantos con más de uno (serían siempre hijos menores de 30 años).

- En otros 9 ejemplos algún sucesor residía en el caserío junto a sus padres y, normalmente, no tenía familia. El resto de los hermanos habitaba fuera, aunque acudian habitualmente a ayudar en los trabajos de la explotación. En otros tantos, los padres, mayores de 50 años, vivían solos, aunque sus descendientes acudian habitualmente a casa. Dentro de este grupo, además, podemos señalar otros tres en los que los hijos acudían de manera esporádica.

- En 4 ejemplos habitaba población mayor de 50 años sola, soltera o sin hijos, y no recibían la colaboración de familiares más jóvenes. En otros 6 se daban problemas de propiedad entre hermanos o entre arrendatario y propietario. En 
estos ejemplos no se ha valorado la situación posible de la familia en relación a la heredad.

Partiendo de este escenario, observamos que en aproximadamente la mitad de las unidades familiares o residen más de dos hermanos con edades entre 30 y 50 años o, aunque no vivan, acuden habitualmente e incluso ayudan en las labores agrícolas. En éstos, es más que probable que los bienes inmuebles del caserío se distribuyan entre los descendientes.

En una cuarta parte de los casos todo apunta a que es una única persona la que recibirá la propiedad de los padres o tíos. El caserío se mantendrá en su integridad. Aun así tampoco podemos confirmarlo dado que desconocemos la composición familiar de esas explotaciones. Es posible que existan beneficiarios que no colaboren en los trabajos agrícolas pero que reciban una parte del dominio. Sin embargo, no es ésta la situación futura que ellos mismos plantean y previsiblemente la heredad se les traspasará en su integridad.

En otros tantos todavía es pronto para evidenciar una situación puesto que los hijos son menores de 30 años. Sin embargo, al ser más de uno, es previsible que, de continuar la tendencia actual, se pueda completar la división de los bienes inmuebles, aunque no a medio plazo.

De confirmarse las afirmaciones que Arrieta observaba en Oiartzun, así como la extensión generalizada del fenómeno que planteamos, se materializará la división de la base territorial en propiedad. Todo parece indicar que en la primera década del año 2000 se va a consumar este proceso y nos vamos a encontrar con una vivienda cada vez menos aislada, más nueva, con menor base territorial y con una explotación agrícola o inexistente o marginal. El caserío, tal y como lo conocemos actualmente, se encontraría en su fase final.

Pocos son los caseríos que pueden escapar de esta situación. Ni siquiera aquéllos que emplean algún hijo dedicado a tiempo completo a actividades agroganaderas se libran del problema del reparto de la herencia ${ }^{16}$. Tampoco ésta es una realidad exclusiva del agro vasco. Comas d'Argemir y Contreras analizando el cambio social del medio rural español señalan la inseguridad que tiene el hijo que quiere continuar con la explotación, que se encuentra con que en el momento en que han fallecido sus padres, porque han muerto sin testar o porque así lo han dispuesto, han de partir la heredad con el resto de sus hermanos y hermanas que viven fuera y no han aportado nada a la explotación familiar, viéndose así sin compensación y además con el peligro de desintegrarse la hacienda (1996).

Los esfuerzos por evitar este problema son importantes. En Gipuzkoa, tras un consenso político y social general, la Diputación Foral ha remitido a la Cámara Vasca una ley por medio de la cual el cabeza de familia podrá nombrar un único heredero, sin 
que el resto de los descendientes pueda recurrir la decisión ante los tribunales. Esta modificación del Fuero ha sido aceptada el 18 de junio de 1999. Permitirá que en algunas explotaciones los padres decidan premiar probablemente a aquél que vaya a continuar manteniendo una actividad agroganadera considerable, en cuanto que está necesitado de esa base territorial.

Pensamos, sin embargo, que esta decisión aunque importante, no va a modificar la tendencia que hemos observado puesto que, por un lado, pocos son los casos en los que el hijo depende de la actividad agroganadera, y por otro, porque actualmente aunque puedan testar a favor de uno de ellos al menos parcialmente, no lo hacen. La heredad se tiende a repartir a partes iguales entre los miembros familiares.

Por tanto, si la estructura social en la que se asentaba el caserio, el mayorazgo, comienza a cambiar a mediados del siglo XIX y, especialmente, a partir de la industrialización del país, sus efectos en la distribución de la propiedad empiezan ahora a materializarse, paralelamente a la consumación del cambio generacional en el caserío. Como consecuencia, asistimos al inicio de una fracturación masiva del dominio, a la que contribuye la especulación urbana y la idea cada vez más extendida que identifica medio rural y calidad de vida. La proximidad a la ciudad impulsa este fenómeno en una comarca de distancias muy reducidas.

La actividad agroganadera cuenta, también en este caso, con otro problema de difícil solución. No es el medio rural el que está en crisis sino la labor agrícola que se desarrolla en él y, simultáneamente, un sistema social fundamentado en esta función.

\section{La desaparición del auzolan: el fin de la unidad administrativa del barrio.}

Si el caserío es la estructura socioeconómica primaria del individuo, el barrio constituye la identidad secundaria, aquélla que identifica a la familia con una comunidad más amplia. El concepto de barrio, aldea o "auzoa" ha tenido en la sociedad rural vasca una importancia transcendental como unidad organizativa de la vida social de sus habitantes ${ }^{17}$. Fruto de ello, surgen toda una serie de relaciones con pleno carácter institucional. Una de las más representativas es el auzolan, o trabajo comunitario, mediante el cual se mantenía y se mejoraba el patrimonio de la aldea.

Douglass (1977) a lo largo de la década de 1960, analizó la estructuración social de dos aldeas vascas, Murelaga en Bizkaia y Etxalar en Navarra. La unidad organizativa del barrio es uno de los elementos principalmente resaltados y, junto a ella, el auzolan. 
En Murelaga cada barrio es una unidad territorial diferenciada en la que los caseríos se encuentran en una proximidad física. Constituye el principal escenario para la actividad económica y para la interrelación social en niveles superiores a los del grupo doméstico. Posee una rudimentaria estructura religiosa (una ermita) y política. En esta última se asienta el auzolan, en la que cada familia, en función de una rotación, desempeña una labor determinada. El cargo principal es el de "etxekojaun", responsable de organizar las actividades comunitarias ${ }^{18}$.

Los principales trabajos que se ejecutan en auzolan están orientados a mantener y mejorar las vías de comunicación, aunque también se realizan depósitos de agua o se repone el tendido eléctrico. Pero siempre son labores dirigidas a reparar bienes que pertenecen a todos ${ }^{19}$.

Al encargado le corresponde organizar la actividad del grupo. A él le toca calcular lo que se precisa para materiales de construcción, comprar lo necesario y atribuir a cada grupo doméstico la cuota del costo. Cada familia debe enviar a un miembro y si no lo hace es multada con una cantidad equivalente al trabajo de un adulto.

La organización de Etxalar es relativamente distinta. Los caseríos están más diseminados, a considerable distancia unos de otros en algunos casos. Aquí no existe el barrio como unidad territorial claramente delimitada por las casas que lo integran. Sin embargo, el esfuerzo comunal, el auzolan, se mantiene, preferentemente orientado a la mejora y conservación de los caminos rurales. Ahora bien, es el ayuntamiento el que organiza esta actividad en las distintas partes de la aldea y es allí donde se adoptan las decisiones en torno a lo que se ha de realizar. El aguacil es el que avisa a los vecinos, ordena el trabajo y, en determinados casos, multa al que no acude.

Otras relaciones indicativas, ligadas al concepto de barrio, también se repiten en ambos ejemplos: relaciones de proximidad, como caseríos a los que avisar en caso de necesidad; económicas, orientadas a la colaboración en labores agrícolas; o de vecindad, dirigidas a ayudar en acontecimientos familiares importantes.

Este sistema de organización socio-territorial, con salvedades en función de la mayor o menor diseminación del caserío o de la topografía más o menos abrupta, se repite en lo esencial en todo el ámbito dominado por el caserío vas $\mathrm{CO}^{20}$. Responde, asimismo, a una comunidad que tiene su fundamento social en las relaciones de proximidad y el económico en la agricultura.

Sin embargo, la progresiva pérdida de población, junto a la reducción del número de viviendas habitadas, origina la alteración principal de los modelos organizativos de estos barrios rurales. Volviendo al ejemplo de Etxalar y Murelaga, Douglass observa que el abandono de un caserío rompía el equilibrio tradicional. Esta situación que en Murelaga era poco importante, era fundamental en Etxalar. Las relaciones entre el vecindario se veían dificultadas y el auzolan también se resentía, dado que un 
número reducido de vecinos tenía que hacer frente ahora al mantenimiento de una mayor distancia de viales. La pérdida o marcha de población de un caserío era acogida con decepción. Si económicamente podía ser rentable para el que permanecía puesto que más tierras y comunales quedaban libres, la sensación de vulnerabilidad personal y el mayor aislamiento social provocaban un sentimiento generalizado de pesadumbre (1977, Vol. II: 101-104).

En el periurbano de San Sebastián, en la década desarrollista de los años 60-70, la pérdida de explotaciones es intensa. Sin embargo, el caserío que no es urbanizado se mantiene como vivienda y exceptuando aquéllos ubicados en zonas muy alejadas apenas hay abandonos. Ello nos llevaría a suponer que las relaciones vecinales y el auzolan no tienen por qué verse alterados en este lapso y así parece haber sido, al menos durante las décadas de 1970 y 1980. Según la Asociación de Agricultura de Montaña Behemendi, en 1992 en Hondarribia, Irún, Errenteria, Astigarraga y Donostia se ejecutaron distintos trabajos de pavimentación de viales en auzolan. Hasta ese momento también se habían ejecutado trabajos en Oiartzun, Hernani, Lezo y Urnieta. En 1995 tan sólo en Astigarraga se utilizó esta fórmula para pavimentar un camino. A partir de entonces no se ha empleado en ningún caso el auzolan en la comarca de San Sebastián ${ }^{21}$.

La desaparición del auzolan parece marcar el paso de una sociedad agrícola, homogénea, más o menos cohesionada, a una realidad heterogénea, dominada por valores individualistas. Para analizar este proceso en el periurbano de San Sebastián hemos optado por tomar un municipio como referencia y observar en él el funcionamiento de este sistema de organización, así como la evolución que ha tenido en las últimas décadas hasta su desaparición. La villa elegida es Hernani22.

En Hernani, el auzolan ha sido el modo tradicional de conservar el patrimonio público en el medio rural y, principalmente, aquello que más uso común tenía, los caminos rurales ${ }^{23}$. El vecindario en unos dias señalados se reunía para mantener y mejorar la infraestructura que utilizaban, cada uno en función de la zona en la que residía. El trabajo era obligatorio y no se recibía ninguna compensación económica por su realización. Esta modalidad de organización implicaba a todo el medio rural y cada familia aportaba al menos una persona, se beneficiara o no directamente del trabajo realizado.

La población estaba organizada por zonas, normalmente siguiendo el vial que llevaba a sus viviendas. En Hernani existían los siguientes grupos principales:

- Galarreta

- Karabel-Portu-Loidi

- Loidi-Iparragirre

- Loidi-Pardiola
- Santiago aldera-Telleri

- Alberro-Arrikarte

- Lastaola-Usategieta

- Ereñozu-Alkatxuin 
- Loidi-Tolarieta-Aritzala borda

- Karabel-Akarregi-Martindegi

- Errollaburu-Añua
- Olazar-Urmendi

- Zumadi-Juantonenea

- Antziola-Larrabide

En cada eje viario había un responsable de área. Él realizaba los trabajos de capataz y entre otros, era el encargado de organizar las labores, movilizar a la población y coordinar con el ayuntamiento lo que se pretendía ejecutar. Sin embargo, a diferencia de otras zonas, el capataz siempre era el mismo, labor que habitualmente solía pasar de padres a hijos. Inicialmente, eran los vecinos los que asumían todo el trabajo: obtención de la piedra mediante ayuda de bueyes, machaque del material y, posteriormente, extensión y compactación del mismo en el camino.

A partir de la década de los setenta el ayuntamiento comienza a colaborar en estas labores aportando el material, desde el balasto hasta los tubos necesarios para canalizar el agua. El vecindario disponía la mano de obra, se encargaba de ampliar los caminos, de abrir las cunetas y de extender el material.

En la década de los ochenta cambió el modo de materialización de estas infraestructuras. La utilización del coche se generalizó y los caminos ejecutados en auzolan sobre una base de balasto no eran nada adecuados para mantener un uso de ese tipo. Por ello, con el objeto de pavimentarlos, la Diputación Foral de Gipuzkoa comienza a aportar toda una serie de ayudas. Con éstas también se impone una regulación de sus características (anchura, saneamiento, talud, ...) ) $^{24}$.

El auzolan, en este década y especialmente en su inicio, se mantiene en toda su estructura organizativa. Se necesitaba ampliar la base de los caminos, había que volver a echar material y se tenía que abrir un mayor número de cunetas. Al igual que en décadas anteriores, todos los vecinos se organizan y vuelven a tomar parte en este tipo de labores. En algún caso concreto, dado que había por primera vez viviendas que no podian mandar a ningún familiar ya que todos trabajaban en el exterior, pagaban la parte que les correspondía en dinero, normalmente el sueldo de una jornada, cantidad que era cobrada por el ayuntamiento.

A medida que a lo largo de la década de los ochenta se iban asfaltando y hormigonando todos los caminos, el auzolan perdía importancia. Tan sólo comenzaron a quedar los ramales que llevaban a uno o dos caseríos. Estos viales sólo daban servicio a un particular o a una vivienda y ante éstos la disponibilidad del vecindario ya no era tan evidente. Aún así, el Ayuntamiento apostó por utilizar de nuevo el auzolan; la pavimentación de estas vías suponía un costo muy grande y más si se tenía en cuenta que iban a ser utilizados en muchos casos por una única familia. Sin embargo, y a pesar de que la mayoría de los ramales estaban sin pavimentar, la respuesta del vecindario fue reduciéndose progresivamente y ya, en la década de los noventa, salvo excepciones, el auzolan acaba desapareciendo. 
Hoy en día los caminos a ejecutar se hacen mediante contrata, soportando el total del costo de la obra el Ayuntamiento y la Diputación Foral. Todos los trabajos que se realizan, hasta los más sencillos, se encargan en el exterior y los vecinos no aportan ni ayuda ni cantidad económica ninguna para ello, excepto la que abonan a través de sus impuestos.

El proceso descrito deja entrever algunas de las razones que indican la pérdida progresiva de este tipo de estructuras organizativas, originadas por el proceso de apertura y adecuación socio-económica a un espacio cada vez más amplio e interrelacionado.

- En primer lugar, cabe señalar la heterogeneidad actual del caserío. A mediados de los años sesenta aún compartía una serie de necesidades comunes, tanto sociales como productivas. En este momento, no tiene ni una actividad homogénea $^{25}$, ni las mismas satisfacciones que cubrir, y la reducción de las distancias y la relación directa y diaria con el mundo urbano le permite sobrepasar la unidad del barrio, que pierde ahora su anterior función.

- Otro aspecto a resaltar, fruto de la superación de la distancia, es el reforzamiento del individualismo, propio de las sociedades urbanas. En este momento, ante cualquier necesidad se recurre principalmente a la familia, que habitualmente vive en el medio urbano o en otro municipio. Tan sólo en casos de extrema gravedad se acude a un vecino próximo.

- La cada vez mayor presencia de población alóctona impulsa la desaparición de estos modos de organización. Desconocen las estructuras colectivas del medio rural y cuando participan aportan ideas y valores organizativos distintos a los de la población autóctona. Son formas diferentes de comportamiento que acaban introduciéndose en la comunidad local ${ }^{26}$.

- El cambio generacional también afecta a la materialización de este proceso. A diferencia de sus padres, que conocieron un sistema "pre" o "proto" industrial, los más jóvenes se han formado en un medio y en una cultura urbana y nunca han participado en este tipo de estructuras. Con la pérdida de las generaciones mayores desaparece también un modo de organización y vida diferente.

El resultado final es la sustitución de la colaboración vecinal por la aportación municipal. Es al Ayuntamiento al que se le exige ahora la responsabilidad de mantener y mejorar el bien común, de la misma manera que asume el mantenimiento y mejora del medio urbano ${ }^{27}$. Alcanza, además de a los viales, al servicio de abastecimiento de agua, a la recogida de basuras, correo domiciliario, e incluso servicios de carácter sectorial, como retirada de ganado muerto o recogida de plástico del ensilado de hierba utilizado. Un sinfín de comodidades urbanas al alcance de la población rural. 
En este caso, al igual que ocurría con el mayorazgo, los cambios en la estructura económica del país, de agrícola a industrial, e incluso en la propia agricultura, de autoabastecimiento a orientación hacia el mercado, generan alteraciones en la estructura de la comunidad que ha envuelto a este mundo rural. Si atendemos al proceso observado, en primer lugar se materializan los económicos y, en una relación causaefecto, progresivamente los sociales.

\section{Cambio generacional versus cambio social}

La apertura a una agricultura sustentada en las reglas del mercado capitalista ha supuesto, además de la desaparición de un sistema orientado al autoconsumo, la ruptura de la homogeneidad anterior. Observamos como unas explotaciones consolidan y aumentan su capacidad de producción fundamentándose cada vez menos en las posibilidades que el medio les aporta, mientras otras marginan progresivamente esta actividad, sin apenas situaciones intermedias. La labor agroganadera no es ya la actividad principal de la población del caserío del periurbano de San Sebastián y las estructuras sociales sustentadas en ella se ven alteradas o desaparecen.

La influencia del medio y valores urbanos es cada vez más evidente y la proximidad a la ciudad potencia su desarrollo. Las relaciones de proximidad pierden su razón de ser en un medio rural lindante con la ciudad. Se consolida ahora un reparto de la herencia similar al urbano, basado en la igualdad de derecho de todos los hijos de la unidad familiar no tanto porque la ley impulse este tipo de partición sino porque la familia lo asume como justo. En la mayoría de los casos, la inexistencia de una persona necesitada del espacio productivo del caserío facilita el reparto equitativo de tierras, solar y capital.

La pertenencia a un medio o a un grupo también se ve alterada. Los familiares, a pesar de residir en el exterior, acuden, a menudo diariamente, al caserío y ellos se convierten en el verdadero nexo de unión del habitante agrario. La concepción de grupo o de pertenencia a un ámbito territorial deja paso ahora a la familia y a los valores individualistas, concepto más propio de sociedades urbanas.

Estos cambios tienen profundas implicaciones en la sociedad rural y en la estructura territorial de las explotaciones agratias. Con la urbanización social del campo desaparecen las instituciones organizativas tradicionales de la población rural. El auzolan o las relaciones de vecindad dan paso a la familia y al intervencionismo público. Las labores agrarias compartidas, al individualismo y la mecanización. El barrio como entidad dinámica desaparece, siendo sustituido por la comunidad de vecinos, con una organización y comportamiento similar al que encontramos en cualquier barrio urbano. 
La estructura territorial también se ve profundamente afectada. La propiedad del caserío se distribuye bajo criterios de igualdad entre los distintos hijos. El resultado es una excesiva fragmentación que hace aumentar el número de unidades agrarias pero que disminuye y dificulta el desarrollo de explotaciones agroganaderas, necesitadas de una base territorial de la que actualmente carecen. Todo indica que en los próximos años se ve a consolidar este proceso y la fragmentación generalizada se va a materializar. La presión urbana y la demanda de terrenos para la realización de vivienda unifamiliar aislada potencia esta situación y difícilmente se desarrollará una actividad agroganadera en un medio cada vez más urbanizado y parcelado.

Los ritmos en la materialización de la división territorial del caserío merecen una reflexión. Se inician con la industrialización masiva de la Comarca de San Sebastián a partir de los años sesenta, coincidiendo con la apertura del país a una economía de mercado pero no culminan hasta varias décadas después, situándose actualmente en este tránsito.

Todo parece indicar que finalizará con la llegada a la titularidad del dominio del caserío de los hijos de la generación que en los años sesenta tenía una edad próxima o superior a 30 años. Hasta entonces conocieron y compartieron muchos de las características de una comunidad que algunos investigadores han denominado "proton o "pre" industrial. Hasta ellos también llegó la propiedad del caserío básicamente intacta y compartían muchos de los valores de esa sociedad. Sus hijos, sin embargo, normalmente los desconocen. Con la definitiva desaparición de esas generaciones se culminará un proceso que afecta a la población, al espacio productivo, a la actividad y también al espacio social del caserío.

\section{Notas}

1 "Sin embargo, después de unas décadas podemos constatar que lo rural, en la medida en que dejaba progresivamente de corresponderse con lo agrario, no desaparece sino que experimenta una profunda mutación" (Oliva, 1997: 332).

2 Vivir en el campo es sinónimo de calidad ambiental para las sociedades urbanas y consecuencia de ello hasta las sociedades más lejanas como los pueblos celtas del Reino Unido y Bretaña comienzan a aumentar su población a cuenta, preferentemente, de población ya envejecida (Perry, 1987).

3 Orti relaciona la segunda Modernización Agraria Española, producida entre 1959-1986, con el final del campesinado patrimonialista tradicional. Se produce la desintegración de la estructura familiar tradicional y aumenta el éxodo juvenil. De hecho, Orti hace coincidir el inicio de los cambios en la estructura social con la primera modernización agraria española en la que se produce la primera oleada migratoria. Sin embargo, todo parece indicar que la Guerra Civil y el periodo franquista paralizan este período (1997: 95).

4 Conclusión a la que llega un importante número de investigaciones centradas en áreas geográficas muy distintas. Para profundizar en este proceso consultar a Willits (1995); Albrecht (1996); Green et al. (1996); García Sanz (1997); Bryden et al. (2000).

5 Caro Baroja ya señalaba que "en la sociedad vasca la casa tiene un significado primordial. En nuestro tiempo aún, y más hace un siglo o medio siglo" (1977: 8). 
6 Fernández de Larrinoa se hace eco de esta situación resaltando que "las sociedades basadas en la casa, son productos históricos, formas de organización y estructuración social localizables en momentos o períodos concretos" (1997: 380)

7 "A través de estas prácticas consuetudinarias y especialmente a través de la institución del mayorazgo es como la casa vasca logra perpetuarse sin dividirse, dando lugar a un tipo de grupo doméstico que había resultado de la preocupación más importante de la sociedad tradicional: la división del patrimonio, condición indispensable de su sobrevivencia» (Martínez, 1994: 299).

8 Arrieta apunta, sin embargo, que no se extendió a toda la sociedad. "Son los agricultores los que lo asumieron, tanto propietarios como arrendatarios. Estos eran, sin embargo, los grupos principales de la sociedad. (1998: 289).

9 “En la peculiar institución del mayorazgo-segundón, se establece una estructura organizadora socialmente del crecimiento vegetativo. En el País Vasco, sin embargo, aparece una notable peculiaridad recogida en el Fuero de Vizcaya, no expresada en el Fuero de Gipuzkoa, pero sancionada como uso "común" e "inmemorial" y verificada en la documentación compulsada o en el trabajo de campo: el heredero continuador de la línea, "el tronquero", sobre el cual recae el vínculo, es de libre designación del padre. Ello varía la pauta biológica, aunque pueda recaer el vínculo con frecuencia en el primogénito. Independientemente del fortalecimiento de la autoridad paterna que esto supone, se puede elegir al más apto o al más adecuado para el mantenimiento del solar" (Arpal, 1977: 208).

$10 \mathrm{La}$ mujer no quiere continuar ni en el caserío vasco ni, en general, en el medio rural y emigra a la ciudad. Así, "la función del matrimonio e incluso del celibato de los otros hermanos en la familia como elementos de reproducción de la unidad familiar e incluso de la propia jerarquia social, que confiere al heredero el papel representativo de la familia en la sociedad rural se ha roto. La tierra pierde parte de su importancia como base económica y deja de ser, a su vez, un elemento de prestigio que facilite el matrimonio de quienes viven en ella" (Comas d'Argemir y Contreras, 1996: 46).

11 "En este sentido, se puede hablar de una continuidad o altas probabilidades de transmisión, precisamente a través de la socialización familiar, de un sistema de valores, de un "orden ideal": para los nativos en el País hay altas probabilidades de que identifiquen con un sistema "pre o "proton industrial y urbano, nada más que sean mayores de 20 o 60 años" (Arpal, 1979: 99).

12 "Unidad mínima de cultivo: superficie mínima que debe tener una parcela nústica para las labores fundamentales de cultivo. Por debajo de ésta no podrán segregarse parcelas de la finca matriz, siendo nulos, por tanto, los actos o negocios jurídicos, voluntarios o no, por cuya virtud se produzca la división o segregación" (Borrador del P.T.S. Agroforestal y del Medio Natural 1999: 59).

13 Observamos cómo en otras regiones en la que se mantiene la figura del mayorazgo no se divide el patrimonio entre los hijos y, a pesar de los cambios habidos en este modelo de organización, la base territorial de la familia se traspasa generalmente en su integridad. Tan sólo en caso de que sea más de uno el número de hijos que permanecen en el municipio los padres procurarán nuevas viviendas para éstos. Seguramente, si la presión inmobiliaria fuera tan importante o si los hijos vivieran en la proximidad sería mayor su oposición a este reparto de la heredad (Consultar Argudo (1991: 157); Flaquer (1995: 21); Lisón (1995: 261).

14 "Se ha de subrayar que no es este un tema de fácil análisis puesto que la gente lo toma con mucho recelo y, a menudo, lo esquiva, especialmente cuando se trata de profundizar en alguna cuestión "(Arrieta, 1999: 292).

15 Es evidente que este criterio es subjetivo. Muchas veces se adelanta la edad de abandonar la vivienda familiar mientras en otras es posterior. Bien podiamos haber tomado otro criterio, como la edad media a la que se contrae el matrimonio, pero todas rondaban la cifra que nosotros señalábamos.

16 La problemática suscitada por la división de tierras como consecuencia de los problemas de herencia es resaltada por todos los agentes del sector, que la consideran como un auténtico "cáncer" que impide el 
desarrollo y lleva a la desaparición de muchas explotaciones. Distintas publicaciones recogen el parecer de estos agentes (Enba, n 10, 1999, Arclatza, $n^{\circ} 279,1999$, Diario Vasco, 13/06/1999, ...).

17 "La vecindad era en la sociedad tradicional algo más que una costumbre, unas relaciones más o menos estables de cooperación, ayuda mutua, prestación de servicios, etc. Era sobre todo un sistema de organización social fundamentado en dos ejes que lo explican y lo van a desarrollar: la casa y los comunales" (Martínez, 1994: 301).

18 En Hondarribia, Irún y en algún barrio de Oiartzun todavía se mantiene la figura del responsable del barrio o Auzoko alkate. El Ayuntamiento, entre sus funciones, organiza la "comisión de montes" a la que acuden, además de los responsables políticos, los alcaldes de barrio. Al menos, en Hondarribia, estos son elegidos anualmente si bien ya no se mantiene ningún sistema de rotación y los mismos generalmente repiten en el cargo.

19 El auzolan aparece ligado a la historia del caserío y, a menudo, también a la propia vida municipal. Todo parece indicar que las instituciones públicas utilizaban de manera generalizada la participación vecinal en el mantenimiento y mejora de caminos vecinales, participación que, a menudo, era obligación. En una publicación de la Diputación Foral relativa a los caminos vecinales y que data de 1898 señalaba que «Están obligados a la prestación... todo habitante del pueblo, soltero o casado, varón no impedido, de edad de 18 años hasta 60 . En este caso debe la prestación por su persona y además por cada individuo varón no impedido de 18 a 60 años, que sea miembro o criado de su familia, y que resida en el pueblo o en su término, y también por cada carruaje o vehículo de toda especie y animales de labor, de carga, de tiro y de silla que emplee en su labor y en su tráfico dentro del término del pueblon (1898: 33).

20 Dentaletche analiza el organigrama sociológico de las zonas de agricultura del País Vasco Francés. Tras el solar familiar señala el papel particular del primer vecino, el que ocupa la primera casa camino de la iglesia, en los casos de muerte, enfermedad, etc. En una tercera aureola resalta el papel del barrio, como lugar de relaciones y de encuentros religiosos. En el siguiente nivel se situaría la aldea o el valle, como lugar de mercado (Agricultura de Montaña, 1985). La estructuración social que supone la vecindad trasciende del espacio del caserío vasco. En este sentido, Martínez señala: "Esta relación estrecha entre casaterritorio común, pasando por la vecindad no era privativo de los vascos. Se puede decir que ambos lados de los Pirineos gozaban de la misma organización socials (1994: 307).

21 Actualmente, el auzolan ya no funciona. Arrieta así lo recoge en el caso de Oiartzun. A este respecto, señala que *a pesar de que no hay caseríos abandonados en Oiartzun, la institución del barrio casi ha desaparecido. Todavía se observan algunos caseríos trabajando en auzolan pero rara vez ocurre y tan sólo en casos de fuerza mayor. Tal vez, se puedan juntar para instalar caños o arreglar caminos, pero siempre ante necesidades comunes y ante las cuales no responda una entidad pública" (1998: 221).

22 Para la elaboración de esta investigación hemos contado con la información aportada por el guarda rural de Hernani, persona que ha estado dirigiendo estos trabajos en auzolan desde finales de la cécada de los años sesenta. La información ha sido completada con la aportada por la Asociación Behemendi, que desde la década de los noventa gestiona las subvenciones destinadas a obras de mejora rural.

23 La utilización del auzolan en la mejora de viales rurales es generalizada en el País Vasco. En Gipuzkoa, incluso en la Norma Foral de Carreteras 17/1994, se recoge este extremo, donde se señala que las administraciones locales podrán contribuir mediante la facilitación de materiales y otros medios técnicos y económicos a los trabajos que se lleven a cabo en auzolan para la mejora de carreteras y caminos de interés de la comunidad vecinal (Boletín Oficial de Gipuzkoa, $\left.n^{\circ} 229,2 / 12 / 1994\right)$.

24 "La solución con hormigón se viene imponiendo progresivamente a las restantes alternativas, de forma que en el año 1988 ya no se construye ningún camino con triple riego habiendo bajado la pavimentación con aglomerado asfáltico de $25 \mathrm{~km}$. en 1982 a $4 \mathrm{~km}$. en 1989. Una de las razones de este predominio del hormigón es su sencillez de construcción puesto que en la ejecución se utilizaba un procedimiento de trabajo en común existente en el mundo rural vasco: el auzolan, que en euskera significa trabajo no retribuido que se hace para cubrir las necesidades que afectan a la comunidad vecinal, tales como la mejora 
de los caminos, abastecimientos de aguas, o la reparación de ermitas o caseríos que han sufrido un incendio" (Losa y García, 1991: 3).

25 "En Basalgo (Bergara), para 1910, de 68 cabezas de familia, sólo tres (una de ellas el cura) no eran labradores; en los mismos caseríos, para 1977 eran 16 los no labradores y 37 los labradoresn (Arpal, 1979, p. 456). En este sentido, Oliva (1997) con datos actuales observa cómo ula agricultura tampoco es ya la actividad que involucra a la mayoría de los inquilinos rurales, buena parte de sus activos son pluriactivos y un gran número se encuentra ya envejecido. Los agricultores han perdido el peso que ejercían en la comunidad.

26 Nos topamos en Hernani con que la función de alcalde o responsable de un barrio rural ya no la ejerce población de algún caserío de la zona sino vecinos que viven ahora en el medio rural. Su función principal es la de detectar las necesidades y la de solicitar al Ayuntamiento su solución. En ningún caso se plantean fórmulas de auzolan.

27 Recientemente se han dado casos en los que los vecinos solicitaban la mejora de determinados caminos de acceso a fincas privadas. A pesar del carâcter privado del terreno, el Ayuntamiento se ha mostrado dispuesto a aportar el material necesario a cambio de que el vecindario pusiera la mano de obra. No se ha podido llegar a un acuerdo y finalmente, tras cumplir el Ayuntamiento, los interesados contratan la ejecución de las mejoras necesarias (Behemendi, 1999).

\section{Bibliografía y fuentes impresas citadas}

Albrecht, D. E. y Albrecht, S.L. (1996): "Family structure among urban, rural and farm populations: Classic sociological theory revisited". Rural sociology, 61. pp. 446463.

Argudo Periz, J. L. (1991): "La casa en el proceso de cambio de la sociedad rural aragonesa: consideraciones jurídicas." En Zaragoza, Universidad de Zaragoza, pp. $131-170$.

Arpal Poblador, J. (1977): "Estructuras familiares y parentesco en la sociedad estamental del País Vasco". Saioak, 1, p. 203-217.

Arpal Poblador, J. (1979): "Familia, caserío y sociedad rural. Análisis del cambio en un caso guipuzcoano (Vergara,1910-1970)". Saioak, 3, p. 80-123.

Arrieta Urtizberea, I. (1998): "Familia, herentzia, nekazaritza eta ondarea gipuzkoako baserrietan". En Fernández de Larrinoa, K. (ed): Sociedad rural, desarrollo y bienestar. Vitoria-Gasteiz, Universidad del País Vasco, p. 281-302.
Arrieta Urtizberea, I. (1998): Garai berriak baserrian (1930-80). Gizarte ruralaren eta baserriaren bilakaeran gizarte industrialak eragindako aldaketa antropologikoak. Donostia, Universidad del País Vasco, tesis doctoral inédita.

Bryden, J., Boliman, R. (2000): "Rural employment in industrialised countries". Agricultural economics, 22, p. 185-197.

Camarero Roja, L. A. (1997): "Pautas demográficas y espaciales de las transformaciones del medio rural: Ruralidad y agricultura". En Agricultura y sociedad en la España Contemporánea. Madrid, Ministerio de Agricultura, Pesca y Alimentación y Centro de Investigaciones Sociológicas, p. 225-248.

Caro Baroja, J. (1974): "Introducción a la historia social y económica del pueblo vasco". Estudios vascos, VI. San Sebastián. Txertoa.

Caro Baroja, J. (1978): "Sobre los conceptos de casa, familia y costumbre". Saioak, 2, p. 3-14. 
Comas d'Argemir, D. y Contreras, J. (1990): "El proceso de cambio social". Agricultura $y$ Sociedad, 55, p. 5-71.

Dendaletche, C. (1986): "La agricultura vasca de montaña". Agricultura de MontañaForesta'85. Vitoria, Gobierno Vasco, p. 3144 .

Dendaletche, C. (1997): “Ecología y antropología de las montañas. Ensayo de definición de un campo de investigación y de acción". Zainak. Cuadernos de antropologia-etnografia, 14, p. 15-24.

Douglass, W. A. (1977): Oportunidad y éxodo miral en dos aldeas vascas: Echalar $y$ Murelaga. Donostia, Auñamendi, 2 vols.

Firey, W., Loomis, C. P. y Beegle, A. (1957): "The fusion of Urban and Rural". En Hatt y Reiss (eds): Cities and Society, p. 214.

Flaquer, L. L. (1995): Familia i canvi social en una vila de la Catalunya vella. Barcelona. Universitat Autònoma de Barcelona, p. 723.

García Sanz, B. (1994): "Alcance y significado de las entidades singulares de población como concepto para cuantificar la población rural". Revista de Estudios AgroSociales, 168, p. 199-221.

González Encinar, M. A. (1984): La franja rumurbana de La Coruña. Madrid. Universidad Complutense.

Green, G. P., Marcouiller, D., Deller, S., Erkkila, D. y Madison, W. I. (1996): "Local dependency, land use attitudes, and economic development: Comparisons between seasonal and permanent residents". Rural sociology, 61, p. 427-445.

Kayser, B. (1990): La renaissance murale. Sociologie des campagnes du monde occidental. París, A. Colin.

Lisón Arcal, J. C. (1995): "El modelo tradicional de familia oscense en perspectiva". Sociedad y Utopia. Revista de Ciencias Sociales, 6, p. 251-262.
Losa Ciganda, J. M. y García Vélez, J. (1991): Experiencias en caminos rurales en Gipuzkoa. Sobre pavimentos de bormigón en vías murales y urbanas de baja intensidad de tráfico. Donostia, Departamento de Agricultura y Medio Ambiente. Inédito.

Martínez Montoya, J. (1994): "La vida rural vasca desde la antropología social". Pensamiento agrario vasco: mitos y realidades (1766-1980). Bilbao, Instituto Vasco de Estudios Rurales. p. 283.

Oliva Serrano, J. (1997): "Estructuración y reestructuración de espacios y sociedades rurales: nuevas reflexiones sobre unos procesos no esperados". Cuadernos de Antropología-Etnografia. Comunidades de Montaña, p. 321-338.

Orti Benlloch, A. (1997): "Una visión histórica generalista de la sociología agraria en España. las tres modernizaciones del desarrollo capitalista". Agricultura y sociedad en la España Contemporánea. Madrid, Ministerio de Agricultura, Pesca y Alimentación y Centro de Investigaciones Sociológicas. p. 71-108.

Perry, R. (1987): Counterurbanisation: international case etudios of socio-economia cbange in mural areas. Norwich.

Redfield, R. (1947): "The Folk Society". The American Journal of Sociology, 52, p. 287300.

Sancho Hazak, R. (1997): "Estructura demográfica y tipificación de los asentamientos y áreas rurales españolas". Agricultura y sociedad en la España Contemporánea. Madrid, Ministerio de Agricultura, Pesca y Alimentación y Centro de Investigaciones Sociológicas, p. 173-224.

Santana, A. (1993): Baserria. Donostia, Diputación Foral de Guipúzcoa.

Urrutikoetxea, J. (1992): "En una mesa y compañía. Caserío y familia campesina en la crisis de la sociedad tradicional. Irún 17661845". Mundaiz. 